\title{
EFFECT OF THERMO-CYCLING ON MICRO-TENSILE BOND STRENGTH OF BULKFILL RESIN COMPOSITE USING RECENT UNIVERSAL ADHESIVE
}

\author{
Maha S. Othman *
}

\begin{abstract}
Statement of the problem: bonding performance of newly launched universal adhesive recommended by the manufacturer to be used with sonically activated bulkfill resin composite need further investigation.
\end{abstract}

Materials and Methods: A total of 40 non carious human molar teeth were extracted and collected from diabetic patients for this study. The selected teeth were divided into two main groups, 20 teeth each, according to adhesive used (A). In group ( $\left.\mathrm{A}_{1}\right)$, the adhesive system was universal one step self- etch adhesive (OptiBond Universal), while in group $\left(\mathrm{A}_{2}\right)$, two steps universal self etch primer adhesive (OptiBond XTR) was applied. Each group was subdivided into two subgroups, 10 teeth each, according to whether thermocycling was carried out or not $(\mathrm{T})$. Where $\left(\mathrm{T}_{0}\right)$ class denotes the teeth that were not subjected to thermocycling and $\left(\mathrm{T}_{1}\right)$ class denotes the teeth there subjected to thermocycling. (SonicFill 2 bulkfill resin composite) restorative material was used with both adhesives. The teeth stored in distilled water for 24 hours before the rod specimens were prepared for the microtensile bond strength test. Two rods from each tooth were obtained. Half of the specimens of each group were subjected to theromcycling testing at $5^{\circ} \mathrm{C} \pm 2^{\circ} \mathrm{C}$ to $55^{\circ} \mathrm{C} \pm 2^{\circ} \mathrm{C}$ for 500 cycles. Microtensile bond strength test was carried out using a universal testing machine.

Results: showed that the mean microtensile bond strength of one step universal self-etch adhesive (OptiBond Universal) had statistically significantly higher value than the self-etch primer (OptiBond XTR) either with thermocycling or without thermocycling at $(\mathrm{P}<0.001)$. The mean microtensile bond strength of one step universal self etch adhesive had statistically significantly higher value without thermocycling than with thermocycling at $(\mathrm{P}<0.001)$. The microtensile bond strength test with the two steps universal self-etch primer (OptiBond XTR) adhesive showed that there was no statistically significant difference between mean microtensile bond strength either with or without thermocycling $(\mathrm{P}=0.067)$.

Conclusion: The (SonicFill2) resin composite one of the recently used bulkfill resin composite restorative material performed higher bond strength with one step universal self etch adhesive more than with two steps universal self-etch primer adhesive when applied to the dentin substrate. However concerning bond stability, the SonicFill2 resin composite restorative material showed higher bond stability after thermocycling with two steps universal self etch primer more than with one step universal self etch adhesive.

KEY WORDS: Universal adhesives - Sonically applied resin composite - Micro-tensile -Thermocycling

*Lecturer of Operative Dentistry, Faculty of Oral and Dental Medicine Cairo University. 


\section{INTRODUCTION}

Resin composites are increasingly used for restorative purpose because of good esthetic and the capability of establishing dependable bond to enamel and dentin. ${ }^{1}$ Innovations in this category ranged between modifications performed in the filler technology until reaching "nanofilled composites". Or innovations performed to technique of application with the introduction of bulkfill resin composite; Sonic- Fill ${ }^{\mathrm{TM}}$ incorporates a highly-filled proprietary nanofilled resin with special modifiers that react to sonic energy. When sonic energy is applied through the hand piece, the modifier causes the viscosity to drop (up to $87 \%$ ), increasing the flow ability of the resin composite enabling quick placement and precise adaptation up to $5 \mathrm{~mm}$ thick increment. When the sonic energy is stopped, the composite returns to a more viscous, non-slumping state that is perfect for contouring and carving. ${ }^{3}$ Researches approved for many years the advantage of the incremental application technique however bulkfill techniques need further investigation to approve its superiority. Researches approved that compositional development leads to simple easy application with reduced chair side time. But its bond strength to the tooth substrates and which adhesive technique is recommended still need more investigation.

All important improvements in bonding have been made in the last 30 years, but still the requirements of an ideal bonding system are quite similar to those indicated by Buonocore. ${ }^{4}$ The bonding mechanism with dentin substrate is mainly depending on the ability of resin adhesives to penetrate into demineralized dentin as a part of the process of bonding restorative materials and the concept of hybrid layer formation was thought to be responsible for the success of dentin bonding. This considered the main bonding mechanism of the total etch adhesive systems. ${ }^{5}$ Concerning the techniquecomplexity and sensitivity, the innovations in the adhesive systems were directed toward a simplified application process. Therefore, the selfetching adhesive system were developed not only to simplify the clinical technique but also to avoid the collapse of the collagen network. ${ }^{6}$ However, this simplified application technique in many time has been reported to be responsible for the adverse affect on the bond strength. ${ }^{7}$

Testing the bonding efficiency of any resinous material could be verified with variety of tests. Microtensile bond strength test become one of the most reliable and widely used established test. Owing to its true bond strength values and higher interface bond strength due to its ability on performing bond strength measurements with fewer cohesive failures in dentin and more adhesive failures. ${ }^{8,9}$

Evaluation of bonding durability is essential since the bond between restoration and tooth substrate is clinically significant only if it is long lasting. Buonocore, in 1981 stated that, in vitro bond strength tests could include thermocycling of the specimens to assess the durability of the bond. ${ }^{10}$

Despite the numerous manufacture claims advantages of the SonicFill 2, the bond strength stability with the newly introduced sonically activated bulkfill resin composite with newly lunched adhesive systems to the tooth still was not clarified in literature. Therefore, this study it seems valuable to evaluate the effect of the simplified newly lunched universal self-etch adhesive (OptiBond Universal) on the bonding efficiency and durability to the recently introduced sonically activated bulkfill resin composite (SonicFill 2) restorative material to dentin substrate.

\section{MATERIALS AND METHODS}

\section{Study design}

A total of 40 non carious sound human molar teeth were collected for this study. Defected or cracked teeth were excluded. The selected teeth 
TABLE (1): Materials used in the study

\begin{tabular}{|c|c|c|c|}
\hline Material & $\begin{array}{c}\text { Product } \\
\text { description }\end{array}$ & Principle components & manufacturer \\
\hline $\begin{array}{c}\text { SonicFill } \\
2\end{array}$ & $\begin{array}{l}\text { Nana hybrid } \\
\text { resin composite }\end{array}$ & $\begin{array}{l}\text { Matrix: } \\
\text { Bis-GMA, TEGDMA, Bis-Ema } \\
\text { Filler: } \\
\mathrm{SIO}_{2} \text {,glass, oxide }\end{array}$ & $\begin{array}{c}\text { Kerr,Orange, } \\
\text { CA, USA } 35183\end{array}$ \\
\hline $\begin{array}{l}\text { OptiBond } \\
\text { XTR }\end{array}$ & $\begin{array}{l}\text { Two step self } \\
\text { etch primer } \\
\text { universal } \\
\text { adhesive }\end{array}$ & $\begin{array}{l}\text { Step one (Primer): } \\
\text { Monomers: } \\
\text { (GPDM), hydrophilic co-momomer including mono and difunctional } \\
\text { methacrylate monomer } \\
\text { Solvents: water, acetone, ethyl alcohol } \\
\text { Photo-initiator: (CQ) based photo-initiator } \\
\text { Step two (Adhesive): } \\
\text { Monomer: } \\
\text { hydrophobic, structural and cross linking monomers } \\
\text { Solvents: Ethyl alcohol } \\
\text { Photo-initiator: (CQ) based photo-initiator } \\
\text { Filler: } 0.4 \text { micron barium glass Nano-silica and Sodium hexafluorosilicate }\end{array}$ & $\begin{array}{c}\text { Kerr,Orange, } \\
\text { CA, USA } 35183\end{array}$ \\
\hline $\begin{array}{l}\text { Optibond } \\
\text { Universal }\end{array}$ & $\begin{array}{l}\text { One step self } \\
\text { etch universal } \\
\text { adhesive }\end{array}$ & $\begin{array}{l}\text { Monomers: } \\
\text { (GPDM) - self-etching adhesive monomer - Co-monomers including } \\
\text { mono- and di-functional methacrylate monomers } \\
\text { Solvents: water, acetone and alcohol } \\
\text { Photo-initiator: (CQ)-based photo-initiator system } \\
\text { Fillers - three nano-sized fillers Fluoride-releasing fillers - sodium } \\
\text { exafluorosilicate and ytterbium fluoride }\end{array}$ & $\begin{array}{c}\text { Kerr,Orange, } \\
\text { CA, USA } 35183\end{array}$ \\
\hline
\end{tabular}

Bis-GMA: Bisphenol A diglycidyimethacrylate, TEGDMA: Triethyleneglycoldimethacrylate, BIS-EMA:Bisphenol Apolyethylene glycol diether dimethacrylate, SIO2: silicone oxide, GPDM: Glycerol phosphate dimethacrylate, CQ: camphorquinone based photo-initiator

were stored in $4^{\circ} \mathrm{C}$ isotonic saline containing $0.2 \%$ sodium azide for a period of maximum one month. 11, 12 Teeth were divided into two main groups, 20 teeth each, according to adhesive technique used (A). In group $\left(A_{1}\right)$, the adhesive system was (OptiBond Universal) self-etch adhesive. Group $\left(\mathrm{A}_{2}\right)$, (OptiBond XTR) self-etch primer adhesive was used. Each group was further subdivided into two subgroups, 10 teeth each, according to whether thermocycling was carried out or not $(\mathrm{T})$. Where $\left(\mathrm{T}_{0}\right)$ class denotes the teeth that were not subjected to thermocycling and $\left(\mathrm{T}_{1}\right)$ class denotes the teeth that were subjected to thermocycling. Prior to thermocycling, the teeth were sectioned to obtain two beams from each tooth, resulting in twenty beams from each subgroup. From each subgroup sixteen beams were used for the microtensile bond strength test and four representative samples for the Scanning electron microscopic (SEM) analysis.

\section{Specimen preparation}

Ready-made cylindrical plastic tubes of $4 \mathrm{~cm}$ height and $1.5 \mathrm{~cm}$ diameter were used for the fabrication of acrylic resin molds (Acrostone Dental Factor, England). Tooth was vertically embedded into self-curing acrylic resin up to the tooth cervical line. Their occlusal plane being parallel to the acrylic resin base, while their long axis being perpendicular to the base of the mold. Occlusal surfaces of the teeth were ground on 
a rotary grinding machine (Unitronic trimmer, $\mathrm{GmbH}$, Germany) with continuous water coolant using 180 grit $\mathrm{SiC}$ papers. ${ }^{13}$ The grinding was performed up to the coronal middle third parallel to the acrylic resin base and perpendicular to the long axis of the teeth in one direction to expose and flatten the sound dentin.

The prepared dentin surfaces were dried without desiccated using oil free compressed air for 5 seconds. Applications and light curing of the dental materials were done according to the manufacturer's instruction. In the first group $\left(\mathrm{A}_{1}\right)$ (OptiBond Universal) Self-etch adhesive was applied using a microbrush, in a form of two consecutive coats with generous amount. Each coat was scrubbed for 20 seconds then dried gently with oil free air for 10 seconds to evaporate the solvents then light cured for 10 seconds. In the second group $\left(\mathrm{A}_{2}\right)$ (OptiBond XTR) self-etch primer adhesive was applied in to two steps. First the primer was applied using microbrush with moderate scrubbing motion for 20 seconds then dried with gentle followed by medium oil free air to evaporate the solvents. Then the adhesive was applied with gentle agitation for 15 seconds using microbrush and air dried with gentle followed by medium air, to evaporate the solvents. Light cured for 10 seconds. Light curing was done using Elipar Free light 2 LED Light curing unit $\left(\mathbf{1 , 2 2 6} \mathrm{Mw} / \mathbf{c m}^{2}\right)$ (3M ESPE, N301289, St Paul MN, USA).

The (SonicFill 2) resin composite restorative material (Kerr/Kavo, 3691651, Bismarckring, Biberach) was activated and applied in a single 5 $\mathrm{mm}$ increment (one-step sonically activated bulkfill technique)which was standardized by using an AutoMatrix band (Dentsply/Detrey Gmbh, Germany). The matrix was labeled from its inner surface at the level of $5 \mathrm{~mm}$ to ensure that standardized increment thickness. The composite delivered by a small nozzle through the ultrasonic application device. Upon deactivation of the sonic energy, viscosity of the resin composite increases and allows easy adaptation. A celluloid matrix strip was used on the top before light curing to ensure smooth surface and prevent the formation of an oxygen inhibited layer. ${ }^{14}$ Light cured for 20 seconds using Elipar Free light 2 LED Light curing unit $\left(1,226 \mathrm{Mw} / \mathrm{cm}^{2}\right)(3 \mathrm{M}$ ESPE, N301289, St Paul MN, USA). Light cure Restorations were polished using Sof-Lex Disk System (Brown/ Orange/ Light Orange/Yellow, 3M ESPE, N301289, St. Paul, MN, USA). There was only one operator performing all restorative procedures.

Each tooth with the acrylic resin cylinder was mounted and sectioned on the cutting machine (Bronwill), (E. McGrath Inc, 35 Osborne Street Salem MA) into a series of $1 \mathrm{~mm}$ thick slabs under water cooling. The sectioning was performed using a diamond disc of $0.3 \mathrm{~mm}$ thickness (IPDB40305, MTI Corporation 860 South 19th Street, Richmond, USA). Then, by rotating the tooth $90^{\circ}$ and again sectioning it lengthwise, sticks of $1 \mathrm{~mm}^{2}$ cross-section area were obtained through the sound dentin. Following the beam preparation, selection of the testing region was carefully performed by visual and stereomicroscope observations (Leica Microsystem Ltd, Heerbrugg, Germany). To standardize the thickness of the beam and the depth of the remaining dentin thickness, a caliper was used to confirm that the cross section area of the beam was $1 \mathrm{~mm}^{2}$, and the amount of dentin remaining between the bonded dentin surface and the region of the pulp chamber was $2 \pm 0.5 \mathrm{~mm}$.

\section{Thermocycling test}

The specimens were stored in distilled water at $37^{\circ} \mathrm{C}$ for one week and then half of the specimens of each group exposed through thermocycling 500 cycles between $5^{\circ} \mathrm{C}$ and $55^{\circ} \mathrm{C}$ with a dwell time of 30 seconds in each water bath and 10 seconds transfer time from one bath to another using thermocycling machine following the recommendation of the international organization for standardization, and no further treatment. ${ }^{15,16}$ 


\section{Microtensile bond strength test}

For microtensile bond strength measurement: A universal testing machine (Llyod instruments Lld, fareham UK) was used. Each beam was attached to the specially designed attachment jig and has its ends glued with cyanoacrylate adhesive (Zapit, Dental Ventures of America Inc. 217 Lewis Court Corona, CA. 92882). The attachment jig consisted of two stainless steel articulating members, fixed part (A) and moving component (B). The upside-down U-shaped (A) encloses an exactly (frictionless) fitting bar (B), which are connected through a $0.35 \mathrm{~mm}$-thick brass sheet glued at the back side of both compartments. The brass sheet allows hinge movements of (B) when force (F) is applied to (B) via a rod and ball. ${ }^{17}$ The testing device was in turn mounted onto the lower fixed compartment of a materials testing machine (LLOYD instruments, LR5K, England) with load cell of $5 \mathrm{KN}$.

Data were recorded using computer software (Nexygen-MT Lloyd instruments). A tensile load with compression mode of force was applied via materials testing machine at a crosshead speed of $0.5 \mathrm{~mm} / \mathrm{min}$. The applied tensile force resulted in debonding along the substrate-adhesive interface. The load required for debonding of each stick was recorded in MPa (Newton divided by the area). ${ }^{9}$

\section{Scanning electron microscopic (SEM) analysis}

Four representative samples from each subgroup either (with or without thermocycling) was observed. The specimens were then placed on stainless steel stubs and examined by Quanta Environmental Scanning Electron Microscope (QESEM) (Quanta FEG 450, Amesterdam, Nether-land). Representative SEM micrograph was taken at magnification $1000 \mathrm{X}$ and at voltage 15.00 $\mathrm{KV}$, to identify the quality of the dentin interface.

\section{Statistical analyses}

Linear regression model with two-way analysis of variance (ANOVA) was used in testing significance for the effect of adhesive system technique, thermocycling and their interaction on the mean microtensile bond strength. Tukey's posthoc test was used for pair-wise comparison between the means when ANOVA test is significant. The significance level was set at $\mathrm{P} \leq 0.05$. Statistical analysis was performed with SPSS 15.0® (Statistical Package for Scientific Studies) for windows.

\section{RESULTS}

Table 2 and Figure 1 represent the descriptive statistics and test of significance comparing the effect of adhesive system and thermocycling on the mean microtensile bond strength values of SonicFill 2 restorative material to dentin. Descriptive statistics and test of significance were performed using twoway ANOVA and Post hoc Tukey's test.

The mean microtensile bond strength with self-etch and without thermocycling was $35.3 \pm$ 6.3 MPa while with thermocycling was $30.4 \pm 5.1$. The result showed that the mean microtensile bond strength of self etch adhesive had statistically significantly higher value without thermocycling than with thermocycling at $(\mathrm{P}<0.001)$. The mean microtensile bond strength with self-etch primer and without thermocycling was 26.2 $\pm 6.9 \mathrm{MPa}$ while with thermocycling was $20.7 \pm 7.3 \mathrm{MPa}$. The result showed that there was no statistically significant difference between mean microtensile bond strength either with or without thermocycling $(\mathrm{P}=0.067)$

TABLE (2) Descriptive statistics and test of significance comparing the mean microtensile bond strength values of SonicFill 2 restorative material to dentin using the two different universal adhesives used in the study

\begin{tabular}{|l|c|c|c|}
\hline \multicolumn{1}{|c|}{ Variable } & Mean & SD & P-value \\
\hline $\begin{array}{l}\text { With one step self-etch adhesive } \\
\text { with thermocycling }\end{array}$ & 32.85 & 7.3 & \\
\hline $\begin{array}{l}\text { With two steps self-etch primer } \\
\text { without thermocycling }\end{array}$ & 23.45 & 5.1 & $<0.001^{*}$ \\
\hline
\end{tabular}




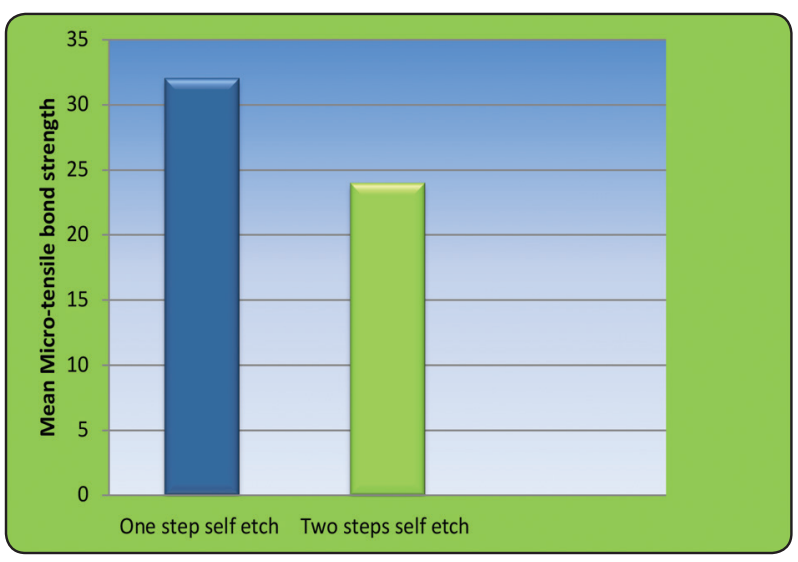

Fig. (1) Bar chart representing the mean microtensile bond strength values of the Universal adhesives being studied

TABLE (3) Descriptive statistics and test of significance comparing the effect of adhesive system and thermocycling on the mean microtensile bond strength values of SonicFill 2 restorative material to dentin

\begin{tabular}{|l|c|c|c|}
\hline \multicolumn{1}{|c|}{ Variable } & Mean & SD & P-value \\
\hline $\begin{array}{l}\text { With one step self-etch adhesive } \\
\text { without thermocycling }\end{array}$ & 35.3 & 6.3 & \multirow{2}{*}{$<0.001^{*}$} \\
\cline { 1 - 2 } $\begin{array}{l}\text { With one step self-etch adhesive } \\
\text { with thermocycling }\end{array}$ & 30.4 & 5.1 & \\
\cline { 1 - 2 } $\begin{array}{l}\text { With two steps self-etch primer } \\
\text { without thermocycling }\end{array}$ & 26.2 & 6.9 & \multirow{2}{*}{0.067} \\
\cline { 1 - 2 } $\begin{array}{l}\text { With two steps self-etch primer } \\
\text { with thermocycling }\end{array}$ & 22.7 & 7.3 & \\
\hline
\end{tabular}

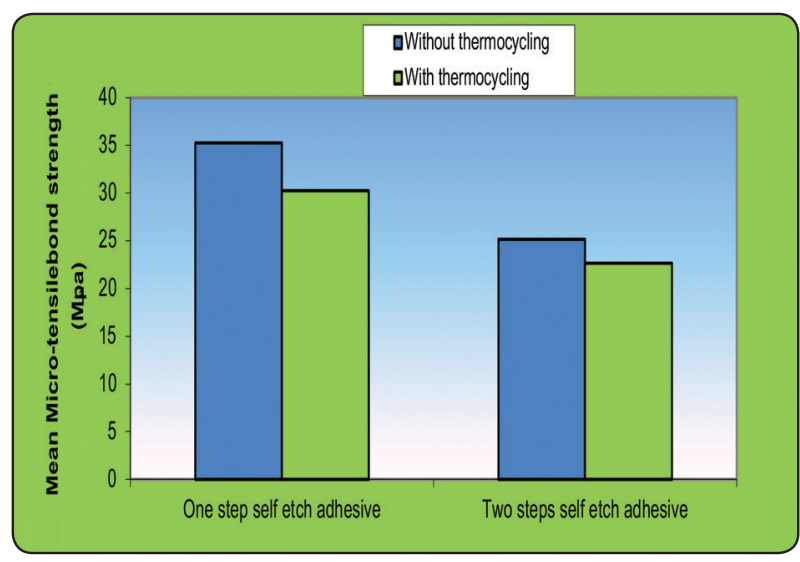

Fig. (2) Bar chart representing the effect of adhesive system and thermocycling on the mean microtensile bond strength values of SonicFill 2 to dentin substrate.

With one step self-etch and without thermocycling there was $69 \%$ adhesive failure, $31 \%$ adhesive cohesive failure while with thermocycling there was $81 \%$ adhesive failure and $19 \%$ adhesive cohesive failure. With two steps self etch primer and without thermocycling there was $63 \%$ adhesive failure, $37 \%$ adhesive cohesive failure while with thermocycling there was $56 \%$ adhesive failure and $44 \%$ adhesive cohesive e failure, while there was no cohesive failure either with one step self etch or two steps self-etch adhesive.

Table (4) Comparison between failure modes with and without thermocycling

\begin{tabular}{|c|c|c|c|c|c|c|}
\hline & Thermocycling & Failure mode & Without & cling & With Therm & ling \\
\hline & $\begin{array}{l}\text { Adhesive } \\
\text { system }\end{array}$ & Adhesive cohesive & Frequency & $\%$ & Frequency & $\%$ \\
\hline \multirow{6}{*}{ Dentin } & \multirow{3}{*}{$\begin{array}{l}\text { Self etch } \\
\text { adhesives }\end{array}$} & Adhesive & 11 & 69 & 13 & 81 \\
\hline & & Cohesive & zero & & zero & \\
\hline & & Adhesive cohesive & 5 & 31 & 3 & 19 \\
\hline & \multirow{3}{*}{ self etch primer } & Adhesive & 10 & 63 & 9 & 56 \\
\hline & & Cohesive & zero & & zero & \\
\hline & & Adhesive cohesive & 6 & 37 & 7 & 44 \\
\hline
\end{tabular}




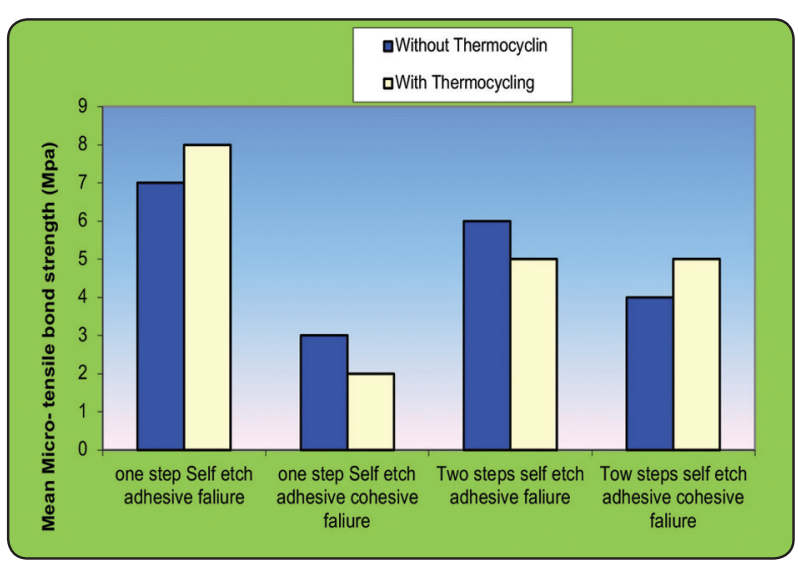

Fig. (3) SEM image for one point at the dentin/restoration interface representing OptiBond Universal (onestep etch adhesive) without thermocycling.

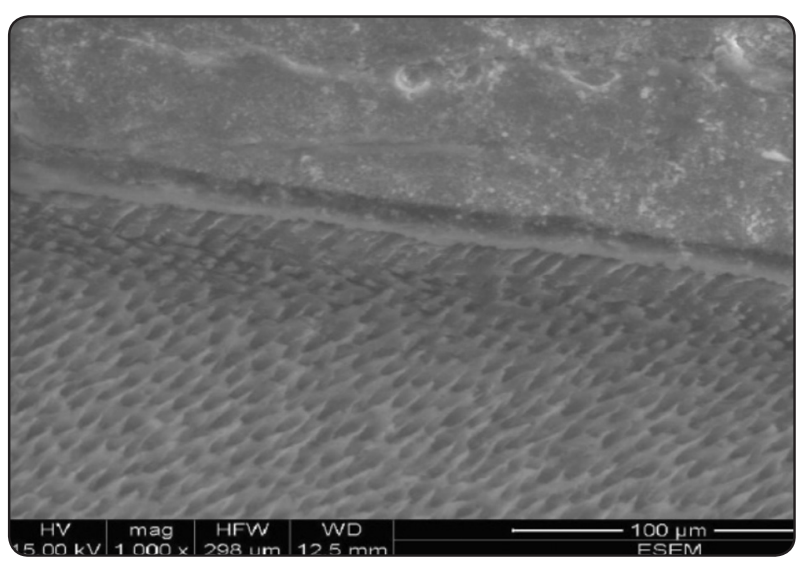

Fig. (5) SEM image for one point at the dentin/restoration interface representing OptiBond Universal (onestep etch adhesive) with thermocycling.

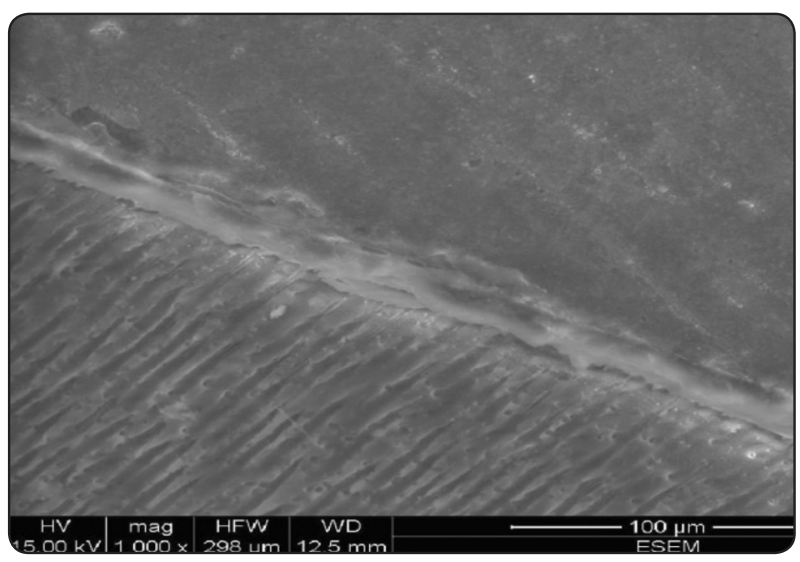

Fig. (7) SEM image for one point at the dentin/restoration interface representing OptiBond XTR (Two-step etch adhesive) with thermocycling.

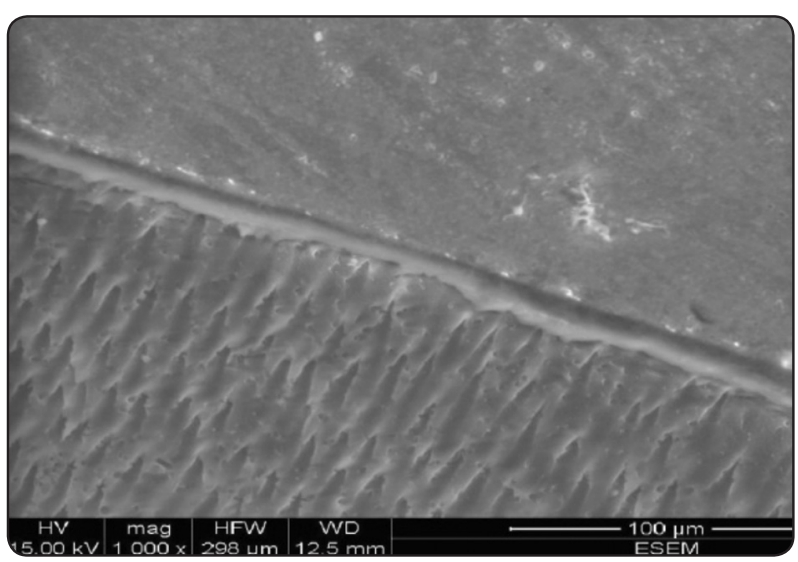

Fig. (4) SEM image for one point at the dentin/restoration interface representing OptiBond Universal (one-step etch adhesive) without thermocycling.

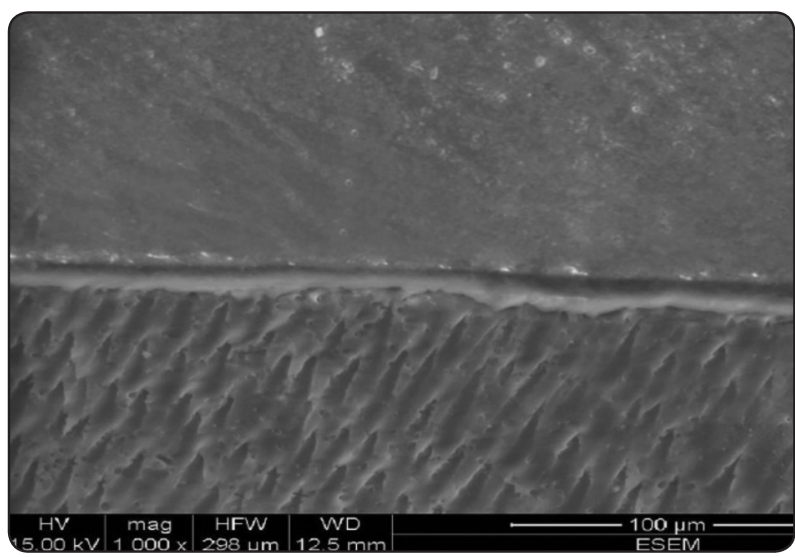

Fig. (6) SEM image for one point at the dentin/restoration interface representing OptiBond XTR (Two-step etch adhesive) without thermocycling.

\section{DISCUSSION}

The application of resin composite can involve a very complex and challenging procedure. Also the induced shrinkage stress of the materials during polymerization may endanger the durability of the bond strength to the tooth structure and consequently, jeopardize the clinical performance of the restorations. ${ }^{17}$ Several factors affect these contraction stresses, including the material compositional factors; matrix type, type of monomer, type and amount of filler, and filler/matrix interaction besides composite polymerization factors; extent and rate of polymerization, curing technique, and technique of placement. ${ }^{18}$ 
For several years incremental technique has been accepted as the a standard technique of resin composite placement in order to compensate for the polymerization shrinkage. ${ }^{19}$ However recently bulkfill resin composite has been used widely owing to its advantage concerning the time saving and less technique sensitivity. There are no more needs for the incremental application due to the presence of modified photoinitiators which can produce complete polymerization up to $5 \mathrm{~mm}$ thickness. ${ }^{20}$ In the same time bulkfill resin composite have low polymerization shrinkage stress due to the presence of what is called stress inhibitors. One type of this recently introduced bulkfill resin composite is the sonicfill. Sonicfill is a one step, bulkfill resin composite that their manufactures (Kerr Corporation) clams that it has ultra efficient curing characteristics that ensure optimal, full $5 \mathrm{~mm}$ depth of cure within 20 second. ${ }^{21}$ Conventional Resin composites exhibit a viscoelastic behavior during polymerization in order to transform from a viscous plastic to a rigid elastic structure. ${ }^{22}$ In the early stages of the polymerization reaction (pre-gel state), viscous flow compensates for most of the curing contraction stresses. At gel point, a continuous network of adequate modulus of elasticity is formed to resist the plastic flow. ${ }^{18}$ As polymerization proceeds to the post-gel state, it is accompanied by a rapid increase in elastic modulus and bridges of covalently bonded molecules form a highly crosslinked network..$^{23}$ However in case of sonicFill resin composite the application of the ultrasonic energy through special hand piece lead to sudden drop in the viscosity (up to 87\%), this increased flow can compensate the polymerization shrinkage stresses of the resin composite, precise adaptation and quick placement. When the sonic energy is stopped, the composite returns to a more viscous, non-slumping state that is perfect for carving and contouring. ${ }^{3}$ This compositional development leads to simple easy application with reduced chair side time.

The rationale behind testing the bond strength is that; the stronger the adhesion between the tooth and the biomaterial, the more the resistant to the stresses imposed during the resin polymerization. ${ }^{24}$ Laboratory bond strength testing is done evaluate the quality of enamel or dentin substrate adhesion with any newly introduced material. The microtensile bond test is considered useful in terms of specimen production and bond test areas can be much better controlled. Furthermore, the small size of the test specimens permits many specimens to be performed from the same tooth thereby promoting more versatile test, more inventive study setups and better control over substrate variables. ${ }^{25}$ Despite of being in-vetro study, however it is highly recommended to take in consideration the stimulation of one of the realistic clinical environment by the application of the thermocycling test.

ISO TR 11450 standards indicate that a thermocycling regimen comprised of 500 cycles in water between $5^{\circ} \mathrm{C}$ and $55^{\circ} \mathrm{C}$ is an appropriate artificial aging test. ${ }^{26}$ The artificial aging effect induced by thermocycling occurs in two ways: First; hot water may accelerate hydrolysis of the interface components, and subsequent uptake of water and extraction of breakdown products or poorly polymerized resin oligmers (Diffusiondependent hydrolysis and elusion). Second, stresses induced by repetitive differential thermal changes (Contraction/expansion stresses). These stresses may induce cracks that propagate along the bonded interfaces, and once a gap is created, changing gap dimensions can cause in and out flow of oral fluids. ${ }^{27}$

The outcome of the microtensile bond strength test clearly indicated that the mean microtensile bond strength of one step self-etch adhesive (OptiBond Universal) had statistically significantly higher value than the two steps self-etch primer (OptiBond XTR) either with thermocycling or without thermocycling at $(\mathrm{P}<0.001)$. There was statically significant difference between the bond strength of the one step universal self etch adhesive system (OptiBond Universal) before and after thermocycling $35.3 \pm 6.3$ Mpa, 30.4 \pm 5.1 Mpa respectively. 
While there was no statistically significant difference in the mean microtensile bond strength of the two steps self etch primer adhesive system (OptiBond XTR) either before or after thermocycling

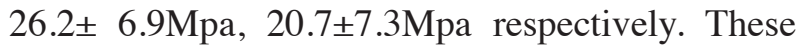
findings are in agreement with the studies of Alex G, 2015 and Rosa et al., 2014. ${ }^{28,29}$

(OptiBond Universal) is a one step universal self etch adhesive system while (OptiBond XTR) can be considered as a universal adhesive but with two steps. There is no "official" definition as to what qualifies as a universal adhesive. Universal adhesives in many times become confused with 7th generation adhesive category (self-etching singlebottle or "all-in-one" systems). Universal adhesives have been described by some manufacturers and opinion leaders as: ideally a single-bottle, nomix, adhesive system that can be used in totaletch, self-etch, or selective-etch mode depending on the clinical situation and the operator personal preferences. ${ }^{30}$ But some time there is a degree of ambiguity exists as to where certain products that are sometimes marketed as universal adhesives actually fit in. For example, (OptiBond XTR) is a two-bottle system that the manufacturer describes on its website as a "self-etch, light-cure, universal dental adhesive".

One reason for the success of currently available universal adhesive systems is the use of hydrophilic monomers that are able to interact with "wet" tooth tissues that are, to some degree, inherently moist. Indeed, this inherently hydrophilic nature of the polymerized adhesive, coupled with residual water that may remain, may act as a semi-permeable membrane permitting water diffusion that, over time, could lead to hydrolysis and breakdown of the adhesive interface. ${ }^{31}$ Another challenge concerning the single bottle is the optimized blend of chemically compatible hydrophobic, adhesive functional with the hydrophilic monomers that would work in a synergistic fashion in order to form a durable polymerized, and hopefully hydrophobic, bonded interface. For that there are significant challenges in striking just the right balance between hydrophilic and hydrophobic character during the construction of single bottle universal adhesive like in (OptiBond Universal). For that an "ideal" dentin bonding agent would be one which is hydrophilic when they first applied (to facilitate interaction with the tooth tissues) then becomes hydrophobic once polymerized (to discourage water sorption). This could result in high initial bond strength which does not remain for a long time after the exposure to the oral environmental factors like $\mathrm{PH}$ cycling or thermocycling.

However, the two-step universal adhesive category like in (OptiBond XTR), there is initial placement of a hydrophilic primer which is then overlaid by a relatively hydrophobic bonding resin. There may be very sound reasons for keeping the chemistry of an adhesive separate until just prior to use in terms of stability and reliable performance, but where does this mixing requirement fit into the definition of a universal adhesive.

$\mathrm{pH}$ of the of the currently available universal adhesives is considered as another challenge. Most current universal adhesives range from 2.2 to 3.2 depending on the product. Universal adhesives are generally considered to have "mild" $(\mathrm{pH}>2)$ or "extra-mild" ( $\mathrm{pH}>2.5)$ etching capabilities. ${ }^{24}$ OptiBond XTR is an example of this category of the mild $\mathrm{pH}$ adhesives, this $\mathrm{pH}$ range adhesives very effective in terms of bonding to dentin. The mineral content of the smear layer of the dentin substrate might have been dissolved and slight alternation of the dentin surface substrate occurred.$^{32}$ Furthermore, in mild self etch adhesives dentin the bonding agent can bond chemically to the organic phase beside its chemical bonding potential to the inorganic phase. However that $\mathrm{pH}$ may not be effective enough to bonding with the enamel (especially to uncut enamel). However the (OptiBond Universal) manufacturer clams that it has a unique nanoetching pattern capable of creating deeper etching pattern for high mechanical retention. This deep etching pattern could be suitable with the enamel 
substrate however with dentin substrate could result in overetching problem without complete infiltration of the monomers through this demineralized subsurface and finally leading to deteriorating initial high bond strength.

The significant effect of thermocycling in case of the one step self etch universal adhesive (OptiBond Universal) may be attributed to that dentin substrate relay in its bonding on both collagen and inorganic portion. Skoog et al., 1998 found that collagen fibers bond chemically to the dentin bonding agent through hydrogen bond. This bond was known to be a weak and unstable bond. ${ }^{33,34}$ In Tay et al., 2001 study, STEM/EDX analysis confirmed that a high concentration of calcium and phosphorous were present in the smear layer. ${ }^{35}$ This increased mineral density could explain the retention of smear layer remnants which may lead to increase bond strength as in single bottle self etch technique but decrease bond stability as the bond mainly occurs to this loosely arranged smear layer. The acids and/ or acidic primers and conditioners used with either total- or self-etching bonding systems do not just remove and/ or disrupt the smear layer but create a thin zone of demineralization, exposing collagen fibrils that are either subsequently (total etch) or concurrently (self-etch) infiltrated with various functional and cross-linking primers and resins. One of the goals in developing a successful adhesive interface is the infiltration and penetration through this acid-demineralized zone with various primers and/ or resins that can be subsequently polymerized by light and/or chemical curing mechanisms.

It is clear that there are some concerns about the ability of universal adhesives to perform as predictably as dedicated primers especially when stressed by aging or thermocycling, and more research is needed that directly compares the two. While clinical trials and clinical experience remains the ultimate test for all dental materials, universal adhesives represent an exciting and promising new class of dental adhesives that the author suspects will soon dominate the adhesive marketplace.
Although in vitro studies are more controlled, they may only be considered as screening tests. It is necessary to simulate intraoral conditions, because in the actual clinical situation the reliability and creditability of any adhesive joint is based upon its maintenance under aggressive oral conditions. Therefore, long term in vivo studies are recommended to evaluate the adhesive joint to tooth substrate.

\section{CONCLUSIONS}

The SonicFill resin composite restorative material performed higher bond strength with the universal one step self-etch adhesive (OptiBond Universal) more than with two steps universal selfetch adhesive (OptiBond XTR). However after thermocycling SonicFill resin composite restorative material showed higher bond stability with the two steps self-etch adhesive (OptiBond XTR) more than with one step self-etch adhesive(OptiBond Universal).

\section{REFRANCES}

1. Manhart J, Hickel R. Esthetic compomer restorations in posterior teeth using a new all-in-one adhesive: case presentation. J Esthet Dent. 1999; 11(5):250-8.

2. Roeters JJ, Shortall AC and Opdam NJ. Can a single composite resin serve all purposes? Br Dent J. 2005; 199(2):73-9.

3. Sybron Dental Specialties Inc., "SonicFillTM System," 2011. www.sonicfill.eu.

4. Kugel G, Ferrari M. The science of bonding: from first to sixth generation. J Am Dent Assoc. 2000; 131 Suppl: 20S-25S.

5. Owens BM, Johnson WW and Harris EF. Marginal permeability of self-etch and total-etch adhesive systems. J Oper Dent. 2006; 31(1): 60-7.

6. Cuevas-Suárez CE, da Rosa WLO, Lund RG, da Silva AF, Piva E. Bonding Performance of Universal Adhesives: An Updated Systematic Review and Meta-Analysis Article J Adhes Dent. 2019; 21(1):7-26. 
7. Tay FR, Suh BI, Pashley DH, Prati C, Chuang SF, Li F. Factors contributing to the incompatibility between simplified-step adhesives and self-cured or dual-cured composites. Part II. Single-bottle, total-etch adhesive. J Adhes Dent. 2003; 5 (2):91-105.

8. Nunes MF, Swift EJ and Perdigão J. Effects of adhesive composition on microtensile bond strength to human dentin. Am J Dent. 2001; 14(6): 340-3.

9. Mandava J, Vegesna DP, Ravi R, Boddeda MR, Uppalapati LV and Ghazanfaruddin MD. Microtensile bond strength of bulk-fill restorative composites to dentin. J Clin Exp Dent. 2017; 9(8): e1023-e1028.

10. Papadogianni D, Dimitriadi M, Zafiropoulou M, Gaintantzopoulou M.D and Eliades G. Universal Adhesives: Setting Characteristics and Reactivity with Dentin. J Mat. 2019; 12(10), 1720.

11. Poptani B, Gohil K, Ganjiwale J, Manisha S. Microtensile dentin bondstrength of fifth with five seventh-generation dentin bonding agents after thermocycling: Anin vitro study. Contemp Clin Dent. 2012; 3(2):167-71.

12. Nakajima M, Sano H, Burrow MF, Tagami J, Yoshiyama M, Ebisu S, Ciucchi B, Russell CM, Pashley DH. Tensile bond strength and SEM evaluation of caries-affected dentin using dentin adhesives. J Dent Res. 1995; 74:1679-88.

13. Tani $\mathrm{C}$ and Finger WJ. Effect of smear layer thickness on bond strength mediated by three all-in-one self-etching priming adhesives. J Adhes Dent. 2002 Winter; 4(4): 283-9.

14. Marchan S, White D, Smith W, Coldero L, Dhuru V. Comparison of the mechanical properties of two nanofilled composite materials. Rev Clin Odontol. 2009; 5(3): 241-246.

15. Li H., Burrow M.F. and Tyas M.J. The effect of thermocycling regimens on the nanoleakage of dentin bonding systems. Dent Mater.2002; 18 (3):189-96.

16. De Munck J., Van Landuyt K., Coutinho E., Poitevin A., Peumans M., Lambrechts P. and Van Meerbeek B. Microtensile bond strength of adhesives bonded to Class-I cavitybottom dentin after thermo-cycling. Dent Mater.2005; 21 (11):999-1007.

17. Eunice C, Margarida A, João C, Filomena B, Anabela, P, Pedro A, Miguel M, Diana R., Joana M, Mário P and Marques F. The evaluation of microleakage of composite resin restorations with SonicFill ${ }^{T M}$. An in vitro experimental model. Open J of Stomato. 2012; 2: 340-347.

18. Braga RR, Ballester RY and Ferracane JL. Factors involved in the development of polymerization shrinkage stress in resin-composites: a systematic review. Dent Mater. 2005 Oct; 21(10):962-70.

19. Soares CJ, Bicalho AA, Tantbirojn D and Versluis A. Polymerization shrinkage stresses in a premolar restored with different composite resins and different incremental techniques. J Adhes Dent. 2013; 15(4):341-50.

20. Lassila LV, Nagas E, Vallittu PK and Garoushi S. Translucency of flowable bulk-filling composites of various thicknesses. Chin J Dent Res. 2012; 15(1):31-5.

21. Ibarra ET, Lien W, Casey J, Dixon SA and Vandewalle KS. Physical properties of a new sonically placed composite resin restorative material. Gen Dent 2015; 63:51-56.

22. McLean D.E.,Meyers E.J and Vandewalle K.S. Enamel Bond Strength of New Universal Adhesive Bonding Agents. J Oper. Dent. 2015;10.2341/13-287-L.

23. Dauvillier B.S, Feilzer A.J, De Gee A.J and Davidson C.L. Visco-elastic parameters of dental restorative materials during setting. J Dent Res. 2000; 79(3):818-23.

24. Van Meerbeek M, Peumans A, Poitevin A, Mine A, Van Ende A and De Munk J. Review- relationship between bond strength tests and clinical outcomes. Dent Mater. 2010; 26:100-21.

25. Ferracane JL. Placing dental composites-a stressful experience. Oper Dent. 2008; 33(3):247-57.

26. Bishara S, Ostby A, Laffon J and Warren J. Shear bond strength comparison of two adhesive systems following thermocycling. Angle Ortho. 2007; 77 (2):337-41.

27. Öz F.D ,Yazıcı A.R and Atalay C. Comparison of different universal adhesives' bond strength to laser-assisted bleached enamel. Selcuk dent J. 2019; 6: 30-37.

28. Alex G. Universal adhesives: the next evolution in adhesive dentistry. Compend Contin Educ Dent. 2015; 36(1):15-26.

29. Rosa WL, Piva E and Silva AF. Bond strength of universal adhesives: A systematic review and meta-analysis. J Dent. 2015; 43(7):765-76.

30. Key opinion leader symposium held at 3M ESPE; July 2014; Wonewok, MN. 
31. Carrilho E, Cardoso M, Ferreira M.M, Marto C, Paula A and Ana Coelho A S. 10-MDP Based Dental Adhesives: Adhesive Interface Characterization and Adhesive Stability-A Systematic Review. J Mat. 2019;12(5), 790.

32. Ozer F., Sengun A., Ozturk B., Say E.C. and Tagami J. Effect of tooth age on microtensile strength of two fluoride releasing bonding agents. J Adhes Dent.2005; 7: 289-95.

33. Helvatjoglu-Antoniades M, Koliniotou-Kubia E and Dionyssopoulos P. The effect of thermal cycling on the bovine dentine shear bond strength of current adhesive systems. J Oral Rehabil. 2004; 31 (9):9115.

34. Zhou W, Liu S, Zhou X, Hannig M, Rupf S, Feng J, Peng $\mathrm{X}$ and Cheng L. Modifying Adhesive Materials to Improve the Longevity of Resinous Restorations. Int. J. Mol. Sci. 2019, 20(3), 723.

35. Skoog DA, Holler FJ, Nieman TA. Principles of instrumental analysis. 1998 